\title{
Experience: the most critical factor in choosing after-hours medical care
}

\author{
H Philips, ${ }^{1}$ D Mahr, ${ }^{2}$ R Remmen, ${ }^{1}$ M Weverbergh, ${ }^{2}$ D De Graeve, ${ }^{3}$ P Van Royen ${ }^{1}$
}

${ }^{1}$ Faculty of Medicine, Department of Primary and Interdisciplinary Care, Centre for General Practice, University of Antwerp, Antwerp, Belgium ${ }^{2}$ Department of Marketing, Faculty of Applied Economics, University of Antwerp, Antwerp, Belgium

${ }^{3}$ Faculty of Applied Economics, University of Antwerp, Antwerp, Belgium

\section{Correspondence to} Hilde Philips, Department of Family Medicine, Centre for General Practice, University of Antwerp, Universiteitsplein 1 , Gebouw R 3de verd, B 2610 Antwerp, Belgium; hilde.philips@ua.ac.be

Accepted 27 January 2009 Published Online First 29 April 2010
ABSTRACT

Introduction In many countries, a reassessment of afterhours primary care has become necessary. In particular, centralised general practitioner deputizing services (GPDS) have emerged. In this study, consumers' preferences for after-hours medical care were obtained and the use of the new GPDS was predicted.

Method On the basis of the Theory of Reasoned Action, a survey was developed that was used at the Free Newborn and Child health care services in Antwerp. Consumers were asked about their knowledge, experience and perceptions concerning the performance of different medical services.

Results 350 questionnaires were used for analysis. $98.6 \%$ of the respondents knew about the existence of the emergency department, whereas the GPDS was known by $81.7 \%$ of the respondents. The main reasons for preferring emergency department over the other services were an easy access, good explanation by the doctor and a late due time of the payment. Respondents preferred the GPDS mainly because of an expected shorter waiting time. Experience had a strong positive influence on choosing a particular after-hours medical service.

Conclusion In our study, the consumers' preferences concerning after-hours medical care were assessed. The following items are crucial for choosing after-hours care: experience with the services, easy access to the service, explanation by the doctor about the illness and the treatment and waiting time.

An overhaul of after-hours primary care has become necessary in many countries. In the future the availability of primary care will decrease due to an overall decreasing number of general practitioners (GPs), feminisation of the profession, working part-time and a decrease of young doctors choosing general practice. $^{1-7}$ The overall result is an increasing workload for GPs. The concept of individual or small groups of GPs offering 24-h care is no longer feasible.

Moreover, the increase of the workload of emergency departments (EDs) is remarkable. EDs show many characteristics of a primary care service, and people visit the ED with problems that can be solved by a GP. Inappropriate use of the ED may distract this service from real medical urgencies. ${ }^{8-10}$

In some countries there is a tendency to centralise after-hours services of GPs. The concept of large-scale general practitioner deputizing services (GPDS) is almost uniformly used in The Netherlands, ${ }^{11}$ Denmark, ${ }^{12}{ }^{13}$ Norway $^{14}$ and in the UK. ${ }^{15-17}$ Concerns have been raised as to whether large-scale GPDS would lead to equally good patient care as the former small-scale model. ${ }^{18}$ It is of particular interest if there is free access to all the medical services and if the primary care can be easily bypassed. Large-scale GPDS, when less appreciated by the patient, could lead to extra transfers of patients from general practice to secondary care alternatives, such as the ED.

In Belgium, with a free access to ED and most medical specialities, GPDS have emerged. In this article, we analyse consumers' experiences with the available services, the importance of service attributes, their perceived performance and the intention to choose after-hours primary care in an urban area. Furthermore, using the model of the Theory of Reasoned Action (TRA), we make an assessment of preferences of consumers among the available services. ${ }^{19}$

\section{ELICITING CONSUMERS' PREFERENCES}

Eliciting consumers' preferences of medical care is difficult but may be studied using marketing techniques. In particular, the TRA is well suited to give insights into consumer behaviour. ${ }^{19-24}$ Hereby, the decision to adopt a particular kind of behaviour (intention to choose a service) depends on a person's behavioural belief (specific attitude towards that choice) and his or her normative beliefs (subjective norm or how reference groups would advise to act).

Using this theory, we identified seven items based on a review of literature and verified them with (1) GPs, (2) academic researchers and (3) patients; five related to the attitude and two related to the subjective norm, which steer behavioural intention (figure 1). ${ }^{25-28}$

According to TRA the attitude towards the intention to choose a service is influenced by the importance of the five service attributes and the people's perceived performance of the different medical services concerning these five service attributes. The perceived performance depends partially on knowledge and previous usage of the services. On the other hand, the opinion of the spouse (or close family members) and of friends (or other family members) will explain the subjective norm. This subjective norm is also influenced by the motivation to comply with both reference groups (figure 1). In our model, attitude towards the choice and the subjective norm have a quantifiable impact on the behaviour concerning decisions of consumers seeking medical care. Importance, perceived performance, motivation to comply and opinion of reference groups were scored by the respondents on a seven-point Likert scale.

We predict the service choice based on the "importance" and the "perceived performance" of the service attributes, as well as on "the motivation to comply with the reference groups" and the "opinion of the reference groups" using the formula in figure 2 . 
Figure 1 Survey items adapted to the TRA by Aizen and Fishbein.22 TRA, Theory of Reasoned Action.

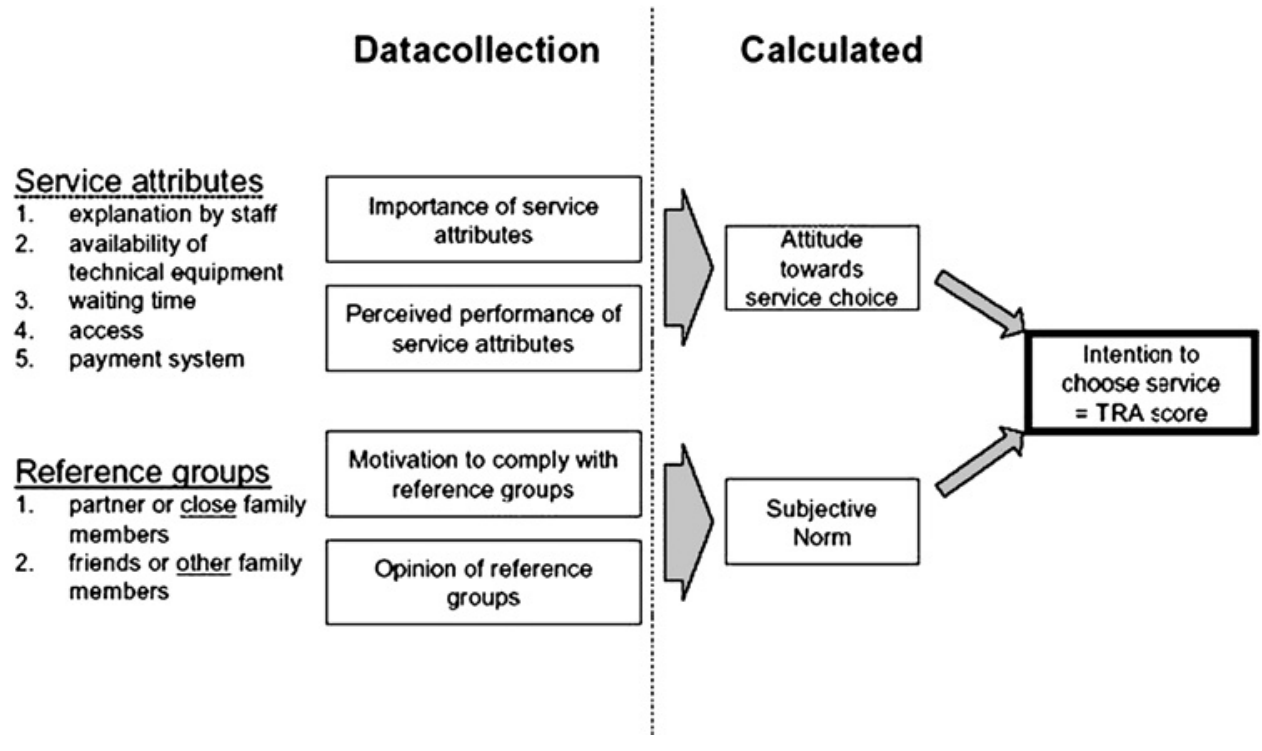

GPDS, request this service for a home visit (GPHV), and visit the $\mathrm{ED}$ or a paediatrician in the case of a child involved (PD). Patients have free access to all services.

As in all European cities, large foreign communities exist, and in Antwerp, the non-Belgian community represents $25.3 \%$ of the
Figure 2 TRA formula to compute behavioural intention. TRA, Theory of Reasoned Action.
$B I_{\text {Senite, }}=A_{\text {Senize, }}+S N_{\text {Senizey }}$

Where:

$$
\begin{aligned}
& A_{\text {Sentice. }}=\sum_{i=1}^{5} \operatorname{ImpAtti.,PerfAtt~i.senvices} \\
& \text { and } \\
& S N_{\text {Serize, },}=\sum_{i=1}^{5} \text { OpiRefGroup:.,ComRefGroupi senvice, } \\
& \text { Blsexizes: behavioural Intention to choose service (=TRA score) } \\
& \text { Asenviares: attitude towards service choice of an individual respondent } \\
& \mathrm{SN}_{\text {sanicos: }} \text { subjective norm related to service choice of an individual respondent } \\
& r \text {. individual respondents }
\end{aligned}
$$

LomRAttix: importance of the attribute

PerfAttisavisac: perceived performance of the attribute for a specific service i: specific attitude, from 1 to 5

\section{ComRefGroupiservices: motivation to comply with reference groups} OpiRefGrounis: opinion of reference groups $j$ : specific normative belief, from 1 to 2

Calculation of the TRA score out of the importance of service attributes and the perceived performance of the service attributes (attitude towards service choice) in combination with the motivation to comply with reference groups and the opinion of reference groups (subjective norm). The number of items for attitudes (5) and the subjective norms (2) reflect their relative contribution to the overall score. 
We would like to know your opinion about the following statements. On this page all the statements are related to the emergency department of the hospital.

Check the box that corresponds most with your opinion.

\begin{tabular}{|c|c|c|c|c|c|c|c|}
\hline & $\begin{array}{l}\text { fully } \\
\text { agree }\end{array}$ & $\begin{array}{c}\text { rather } \\
\text { agree }\end{array}$ & $\begin{array}{l}\text { slightly } \\
\text { agree }\end{array}$ & $\begin{array}{c}\text { neutral } \\
\text { don't know }\end{array}$ & $\begin{array}{l}\text { slightly } \\
\text { disagree }\end{array}$ & $\begin{array}{c}\text { rather } \\
\text { disagree }\end{array}$ & $\begin{array}{l}\text { fully } \\
\text { disagree }\end{array}$ \\
\hline $\begin{array}{l}\text { At the emergency department of the hospital the } \\
\text { required examinations can be done quickly. }\end{array}$ & I & & $\boldsymbol{C}$ & E & & & $\boldsymbol{E}$ \\
\hline $\begin{array}{l}\text { At the emergency department of the hospital the } \\
\text { technical equipment (for medical photos, blood } \\
\text { tests, etc) is quickly available. }\end{array}$ & & & & & & & \\
\hline $\begin{array}{l}\text { The emergency department of the hospital is easy } \\
\text { to reach. }\end{array}$ & & & & & & & \\
\hline $\begin{array}{l}\text { At the emergency department of the hospital I will } \\
\text { not have to pay immediately. }\end{array}$ & & & & & & & \\
\hline $\begin{array}{l}\text { My partner (or some other relative) will decide to } \\
\text { call on the emergency department for this kind of } \\
\text { emergency. }\end{array}$ & & & & & & & \\
\hline \multicolumn{8}{|l|}{$\begin{array}{l}\text { My friends and family will not support the use of } \\
\text { the emergency department of the hospital. }\end{array}$} \\
\hline $\begin{array}{c}\text { For an appointment at the emergency department } \\
\text { of the hospital I will have to wait long. }\end{array}$ & & & & & & & \\
\hline $\begin{array}{l}\text { The doctor at the emergency depatment of the } \\
\text { hospital will give me a clear explanation about my } \\
\text { health problem and the therapy. }\end{array}$ & 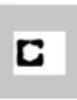 & 7 & 0 & & & & \\
\hline
\end{tabular}

Figure 3 Example of seven items asking for the perceived performance and opinions of the reference groups, in this example, concerning the emergency department.

entire population in 2006. To minimise selection bias, our aim was to cover the broad range of nationalities in this region. We therefore approached all consumers at the Free Newborn and Child health care service (FNC service) in Antwerp. In 2005 this service covered $97 \%$ of the entire newborn population in the city. ${ }^{29}$ Although we only reach a specific part of the population (respondents with young children), we know that these people frequently use out-of-hours care. ${ }^{30}$

\section{Instrument}

Because people may take other decisions in choosing medical services when children are involved, we developed a questionnaire based on two scenarios: the "adult" scenario "You have a visit on a Saturday night from a friend or relative who will stay the night at your home. During the night, the visitor wakes up and feels unwell, in which case you decide to look for medical assistance"), and the "child" scenario ("It is Sunday morning. Your three-year-old child has a fever. You already gave him a medicine to lower the fever. It helped but the fever is coming back. So you decide to look for medical assistance"). ${ }^{27}$ Respondents were allocated alternating to either one scenario. The questionnaire was developed and piloted in three different languages (Dutch, English and Arabic), of which the consistency was checked by means of backward-translation. The questionnaire was administered between February and June 2006. All visitors of the FNC service were requested to participate. Trained interviewers offered the parents a questionnaire that had to be filled out on a laptop and, if needed, extra assistance was offered.

First, the survey asked in four items for experience (knowledge and usage) with after-hours services. Respondents had to score "never heard of", "never used", "used once" and "used several times" for each of the different after-hours services offered: ED, GPDS, GPHV and PD.
Second, the participants were asked to evaluate the importance of the attributes and the motivation to comply with reference groups on a seven-point scale (from "1 unimportant" to "7 "important" at the extremes).

The third part checked the respondents' opinion about seven items concerning each type of service included. The answers were rated on a seven-point scale (7, "fully agree"; 6, "rather agree", 5, "slightly agree"; 4, "neutral/don't know"; 3, "slightly disagree"; 2 , "rather disagree"; 1, "fully disagree"), measuring the perceived performance of service attributes and opinions of the reference groups. In figure 3 an example of this part of the questionnaire is given.

Finally, the respondents answered 19 questions concerning their sociodemographic status.

\section{Analysis}

Data were analysed using SPSS V.13.0. Descriptive statistics of the sociodemographic data of our sample and knowledge and use of the different services were calculated. Means, SD and $95 \%$ confidence interval were used for quantitative variables, frequencies and percentages for categorical variables. We applied one-way analysis of variance (ANOVA) with the adequate post hoc comparison (Dunnett $\mathrm{C}$ for equal error variances and Tukey honest significant difference test for non-equal error variances of the service attribute evaluation) to investigate the means of the perceived performance of the services. The $\chi^{2}$ test for contingency tables was used for comparing proportions. Statistical significance of results is reported as $p$ values.

Following the TRA approach, we computed the respondents' individual TRA score per service and identified the service choice based on the highest TRA score. This was considered the first choice. The accumulation of the first choices over all respondents resulted in the preference shares for ED, GPDS, GPHV and PD. Similar to market shares, it illustrates in percentages the shares of 
Table 1 Sample size, questionnaire language and sociodemographics over both scenarios

\begin{tabular}{|c|c|c|c|c|}
\hline & \multicolumn{2}{|c|}{ Adult scenario } & \multicolumn{2}{|c|}{ Child scenario } \\
\hline Dutch & \multicolumn{2}{|l|}{165} & \multicolumn{2}{|l|}{159} \\
\hline English & \multicolumn{2}{|l|}{16} & \multicolumn{2}{|l|}{6} \\
\hline Arabic & \multicolumn{2}{|l|}{3} & \multicolumn{2}{|l|}{1} \\
\hline Sum & \multicolumn{2}{|l|}{184} & \multicolumn{2}{|l|}{166} \\
\hline Mean age (SD) & \multicolumn{2}{|c|}{31 y $(5.94)$} & \multicolumn{2}{|c|}{31 y $(6.03)$} \\
\hline Married or living together with one child & \multicolumn{2}{|l|}{$42.93 \%$} & \multicolumn{2}{|l|}{$51.81 \%$} \\
\hline $\begin{array}{l}\text { Married or living together with two } \\
\text { or more children }\end{array}$ & \multicolumn{2}{|l|}{$45.11 \%$} & \multicolumn{2}{|l|}{$34.34 \%$} \\
\hline Single with one child & \multicolumn{2}{|l|}{$6.52 \%$} & \multicolumn{2}{|l|}{$5.42 \%$} \\
\hline Single with two or more children & \multicolumn{2}{|l|}{$2.17 \%$} & \multicolumn{2}{|l|}{$2.41 \%$} \\
\hline Other & \multicolumn{2}{|l|}{$3.26 \%$} & \multicolumn{2}{|l|}{$6.02 \%$} \\
\hline Mean number of family members (SD) & \multicolumn{2}{|c|}{$3.60(1.28)$} & \multicolumn{2}{|c|}{$3.52(1.12)$} \\
\hline Mean number of children (SD) & \multicolumn{2}{|c|}{$1.67(0.94)$} & \multicolumn{2}{|c|}{$1.65(1.00)$} \\
\hline Foreign origin & \multicolumn{2}{|l|}{$44.02 \%$} & \multicolumn{2}{|l|}{$44.58 \%$} \\
\hline Mother & \multicolumn{2}{|l|}{$74.46 \%$} & \multicolumn{2}{|l|}{$68.67 \%$} \\
\hline Father & \multicolumn{2}{|l|}{$20.11 \%$} & \multicolumn{2}{|l|}{$22.89 \%$} \\
\hline Others & \multicolumn{2}{|l|}{$5.43 \%$} & $8.44 \%$ & \\
\hline Yes & $82.07 \%$ & & $88.55 \%$ & \\
\hline Degree of education & $\%$ & Cum\% & $\%$ & Cum\% \\
\hline No degree or only primary education & 5.43 & 5.43 & 2.41 & 2.41 \\
\hline Only lower secondary education & 10.33 & 15.76 & 10.24 & 12.65 \\
\hline Higher secondary education & 47.83 & 63.59 & 41.57 & 54.22 \\
\hline Higher non-university & 17.39 & 80.98 & 22.89 & 77.11 \\
\hline University or post-university & 11.41 & 92.39 & 17.47 & 94.58 \\
\hline Don't know & 7.61 & 100 & 5.42 & 100 \\
\hline Compulsory health insurance ${ }^{*}$ & $95.11 \%$ & & $95.78 \%$ & \\
\hline Total N & 350 & & & \\
\hline
\end{tabular}

${ }^{*}$ In Belgium, almost $99 \%$ of the population is covered by compulsory health insurance. ${ }^{31}$ Data for larger cities can differ from national data because of the presence of refugees, asylum seekers and immigrants.

all patients adopting one of the offered services. Moreover, we checked for the significant differences between TRA scores to estimate the strength of the service preference.

To explain the reasons for the first choice, a multigroup discriminant analysis was also applied. The dependent variable was the chosen service, whereas experience and sociodemographic items were the explanatory ones. Moreover, a regression analysis estimated what determines the differences between services. The sociodemographics and the experience items as well as the perceived performance of service attributes and the opinions of the reference groups were used to predict the differences between the services.

\section{RESULTS}

\section{Sociodemographics of the sample}

Data were collected at three FNC services. Non-participation (49.6\% of all visitors) was mainly due to language problems or no interest to participate.

Three hundred and fifty questionnaires were used for analysis. The distribution of scenarios was $52.6 \%$ adult scenario and $47.4 \%$ child scenario (table 1 ).

\section{Experience}

The experience in terms of knowledge ("never heard of") and use ("never used", "used once" and "used several times") did vary across the services. The GPDS was not known by $18.3 \%$ of the 350 respondents, whereas only $1.4 \%$ never heard of the ED. During the past 12 months, $62.3 \%$ of the respondents used the $\mathrm{ED}$ at least once. Of all respondents, $34.9 \%$ already used the GPDS at least once. Overall, the lack of experience is higher for the GPDS and the GPHV than for the other two services. The experience with the paediatrician is highest among all services, especially the repeated use (figure 4).

The experience varied significantly in between the adult and the child scenario for the ED (independent-samples $t$ test $p=0.002)$ and GPHV $(p=0.018)$ but not for the GPDS ( $p=0.216)$. The PD was only available in the child scenario. Because of the mixed results and different choice options, in the following sections, each scenario is analysed separately and interpretation of the results synthesised.

\section{TRA: behavioural intention to choose a service, based on attitudes and the subjective norm}

In both scenarios, people were asked to rate importance and perceived performance for their attitude concerning medical afterhours care of different services on a seven-point scale, as well as motivation to comply with reference groups and opinion of reference groups (figure 1).

\section{Importance of service attributes}

The results are similar for both the adult and the child scenario. The most important factor for assessing a service is "the explanation given by the doctor about the disease and its treatment". The variables "technical examination", "waiting time" and "access to the service" can be grouped as second most important because the difference in their average importance rating is not significant (mean score between 6.23 and 6.33 for the adult scenario and between 6.15 and 6.31 for the child scenario). The least important factor is "immediate payment or payment afterwards" (table 2).

\section{Perceived performance of service attributes Both scenarios}

In general, the ED is more appreciated than the GPDS in terms of "explanation", "access", "immediate technical examination" and "payment". On the other hand, people perceive the GPDS better considering "waiting time". The GPDS is considered better than the paediatrician and the home visit in "payment" and "waiting time". Consumers expect better explanation during a consultation at the ED. In addition, the paediatrician is expected to give better explanation. Both services are also superior to GPDS and GPHV in a prompt examination because of the availability of technical equipment.

\section{Adult scenario}

The attributes "access" to the service and "explanation" by the doctors show the highest performance across all services (table 3). Investigating the differences between the services at a significance level exceeding 0.95 by a one-way ANOVA shows following results: the perceived performance of "access" was rated highest for the emergency department. "Access" also scored highest for the GPDS although lower than for the ED. At the ED, "explanation" scores 5.73 (95\% confidence interval 5.53 to 5.93). "Waiting time" is perceived slightly better at the GPDS than at the ED, whereas "technical examination" scores significantly higher at the ED compared to the GPDS and the GPHV. ED is superior to the other services in all criteria except for "waiting time" (table 4).

\section{Child scenario}

In the child scenario, we find similar results. The attribute that scores highest on perceived performance is "explanation". Here the highest expectations go to the paediatrician (table 5). The ANOVA results in table 6 show at a significance level exceeding 0.95 , ED is perceived better than GPDS in "immediate technical examination", "payment", "access" and "explanation", whereas 
Figure 4 Experience with after-hours services: overall frequencies.

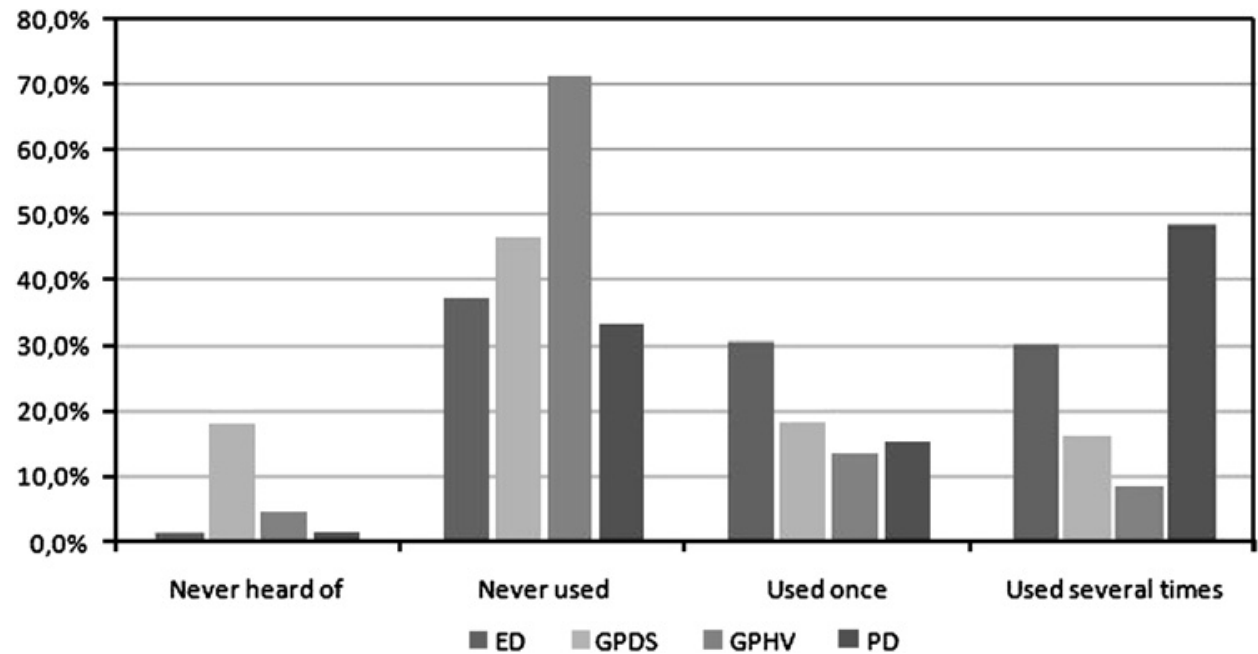

the latter is superior in "waiting time". The comparison of ED and PD shows significant advantages for ED in "payment" and "access" and a lead for PD in "explanation". Moreover, the results of the group comparison indicate an overall preference for both these services.

\section{Motivation to comply}

To compute the TRA score, we obtained the motivation to comply with the reference groups (partner and friends). In both scenarios, consumers consider the partner as more influential for the decision than the friends (table 2).

\section{Opinion of reference groups}

Consumers in the adult scenario believe that partners assess ED higher than GPHV (table 3). When children are involved, respondents assume that both reference groups would recommend PD over GPDS and GPHV (table 5).

\section{Service choice: overall score using TRA and comparison} of the services

Based on the TRA formula (figure 2), we computed the respondents' individual TRA scores per service. Consequently, we are able to rank the different services for every respondent. The TRA approach assumes that patients decide for the service with the highest score. Afterwards, we computed the score means over all respondents. To interpret the power of the margins, we also checked the significances of difference between the scores. The number of items for attitude (five) and the subjective norms (two) reflect their relative contribution to the overall score.

Consumers rate-on average-ED higher than GPDS, although there is no significant difference in the evaluations of

Table 2 Importance of service attribute and motivation to comply in both scenarios: mean and $95 \% \mathrm{Cl}$

\begin{tabular}{|c|c|c|c|c|}
\hline \multirow{2}{*}{$\begin{array}{l}\text { Importance of attribute/motivation } \\
\text { to comply }\end{array}$} & \multicolumn{2}{|c|}{$\begin{array}{l}\text { Adult scenario } \\
(\mathrm{n}=184)\end{array}$} & \multicolumn{2}{|c|}{$\begin{array}{l}\text { Child scenario } \\
(\mathrm{n}=166)\end{array}$} \\
\hline & Mean & $95 \% \mathrm{CI}$ & Mean & $95 \% \mathrm{Cl}$ \\
\hline Explanation & 6.86 & 6.76 to 6.96 & 6.83 & 6.75 to 6.91 \\
\hline Immediate technical examination & 6.33 & 6.21 to 6.45 & 6.28 & 6.13 to 6.43 \\
\hline Waiting time & 6.29 & 6.15 to 6.44 & 6.15 & 5.96 to 6.34 \\
\hline Access & 6.23 & 6.06 to 6.39 & 6.31 & 6.15 to 6.47 \\
\hline Payment & 4.84 & 4.53 to 5.14 & 4.89 & 4.59 to 5.19 \\
\hline Partner/close family members & 5.23 & 4.93 to 5.52 & 5.90 & 5.69 to 6.11 \\
\hline Friends/other family members & 4.02 & 3.71 to 4.33 & 4.28 & 3.97 to 4.59 \\
\hline
\end{tabular}

GPDS and GPHV (table 7). When children are involved, also the paediatrician is preferred over GPDS and GPHV (table 8). The dominance of the ED and PD is consistent over both scenarios, indicating the external validity of the results.

\section{Preference shares for services Full model}

According to the TRA, the highest score determines the service preference for each patient. In addition, we also examined the strength of this commitment. Therefore, we computed the score per service among the participants who prefer a particular service (the preference share), and the significance of differences between the preferred and the other services. We excluded cases when no clear first could be determined, that is, two or more services had equal highest TRA score. It reduced the sample size for both scenarios by 16 (adults, 10; children, 6) to 334 .

The preference shares confirm the expected preference for the ED. Of all patients, $63 \%$ in the adult scenario and $47 \%$ in the child scenario would choose the ED (table 9).

We then applied a multigroup discriminant analysis. The dependent variable was the chosen service, whereas experience (figure 4) and sociodemographic items (table 1) were the explanatory ones. The cross-validated classification results did not show any improvement compared with the naive classification. However, further analysis of the preference shares by means of two group discriminant and regression analysis indicates a strong impact of experience on the service selection, whereas none of the other variables seems to influence the preference significantly. Therefore, we investigated the relation between preference and experience further. Because experience is nominally coded (0: "never heard of" and "never used"; 1: "used once" and "used several times"), cross-tabs and $\chi^{2}$ test to check for dependency between the variables were applied.

The results for the both scenarios suggest that patients with experience in a specific in the GPDS have a higher likelihood to choose that service.

The $\chi^{2}$ test $(n=174, d f=1)$ shows dependency between experience and preference for $\operatorname{ED}\left(\chi^{2}=2.80\right.$, sig=0.094), GPDS $\left(\chi^{2}=12.42, \operatorname{sig}=0.000\right)$ and GPHV $\left(\chi^{2}=3.54, \operatorname{sig}=0.060\right)$ at a 0.10 level. When children are involved in the choice, we also notice correlations between experience and the service choice. The $\chi^{2}$ test $(\mathrm{n}=160, d f=1)$ points out dependency between experience and preference for GPDS $\left(\chi^{2}=9.53\right.$, sig $\left.=0.002\right)$ and PD $\left(\chi^{2}=10.20\right.$, sig $\left.=0.001\right)$ at a 0.01 level but not for $\operatorname{ED}\left(\chi^{2}=0.66\right.$, sig $=0.417)$ and GPHV $\left(\chi^{2}=0.01\right.$, sig $\left.=0.949\right)$. 
Table 3 Perceived performance and opinion of reference group in adult scenario: mean and 95\% Cl

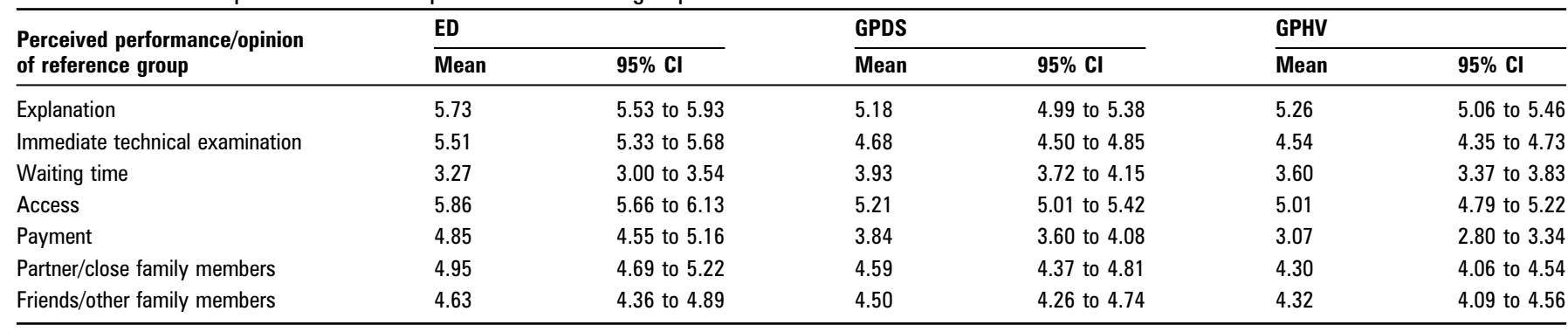

ED, emergency department; GPDS, general practitioner deputizing services; GPHV, GP home visit.

Table 4 ANOVA results for perceived performance and motivation to comply in the adult scenario

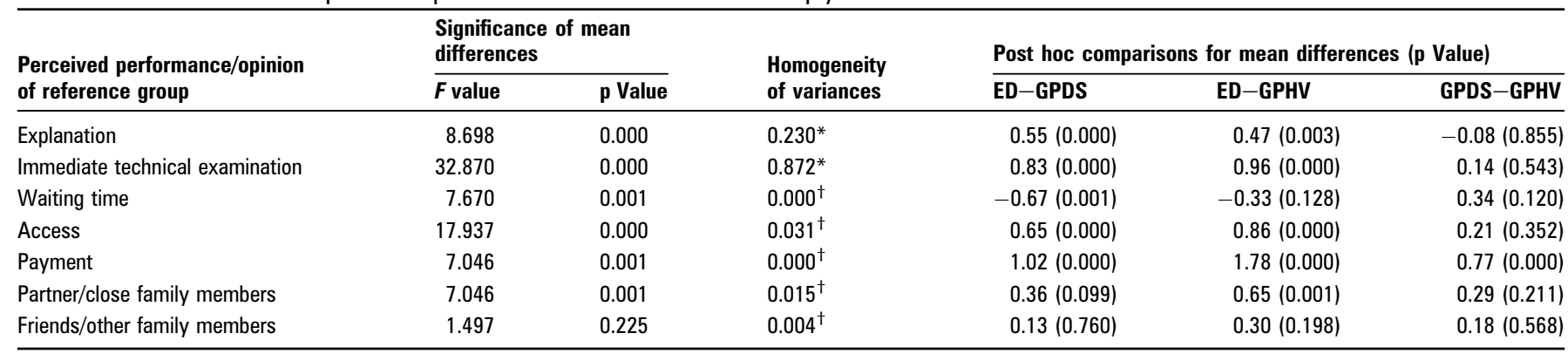

ANOVA, analysis of variance; ED, emergency department; GPDS, general practitioner deputizing services; GPHV, GP home visit.

Applied post hoc test: ${ }^{*}$ Tukey honest significant difference test; ${ }^{\dagger}$ Dunnett $C$.

Table 5 Perceived performance and opinion of reference group in child scenario: mean and $95 \% \mathrm{Cl}$

\begin{tabular}{|c|c|c|c|c|c|c|c|c|}
\hline \multirow{2}{*}{$\begin{array}{l}\text { Perceived performance/opinion } \\
\text { of reference group }\end{array}$} & \multicolumn{2}{|l|}{ ED } & \multicolumn{2}{|l|}{ GPDS } & \multicolumn{2}{|l|}{ GPHV } & \multicolumn{2}{|l|}{ PD } \\
\hline & Mean & $95 \% \mathrm{Cl}$ & Mean & $95 \% \mathrm{CI}$ & Mean & $95 \% \mathrm{CI}$ & Mean & $95 \% \mathrm{CI}$ \\
\hline Explanation & 5.60 & 5.38 to 5.81 & 5.17 & 4.99 to 5.36 & 5.49 & 5.29 to 5.70 & 6.38 & 6.23 to 6.53 \\
\hline Access & 5.95 & 5.76 to 6.15 & 5.11 & 4.91 to 5.32 & 5.01 & 4.78 to 5.25 & 5.00 & 4.74 to 5.26 \\
\hline Waiting time & 3.41 & 3.13 to 3.69 & 4.02 & 3.82 to 4.22 & 3.54 & 3.31 to 3.77 & 3.37 & 3.10 to 3.64 \\
\hline Payment & 4.77 & 4.46 to 5.07 & 3.54 & 3.31 to 3.78 & 2.87 & 2.60 to 3.15 & 2.75 & 2.47 to 3.04 \\
\hline Partner/close family members & 4.67 & 4.38 to 4.96 & 4.33 & 4.07 to 4.58 & 4.28 & 4.03 to 4.54 & 5.11 & 4.82 to 5.40 \\
\hline
\end{tabular}

ED, emergency department; GPDS, general practitioner deputizing services; GPHV, GP home visit; PD, paediatrician.

\section{Restricted model}

Because experience is a strong predictor for the GPDS choice, we restricted the model by using only GPDS-experienced respondents (having visited the GPDS at least once: $\mathrm{n}=70$ (adult scenario), $n=52$ (child scenario)). First, the ANOVA results for TRA score show that the differences between the results of the most preferred services are neither for the adult (ED-GPDS: difference in TRA score $0.53, \mathrm{p}=0.997$ ) nor for the child scenario (ED-GPDS: difference in TRA score 1.45, $\mathrm{p}=0.998$; GPDS-PD: difference in TRA score: $6.47, p=0.876$ ) significant at a 0.05 level. This indicates that patients do not have a strong preference for ED or PD over GPDS once the GPDS has been experienced.

Furthermore, the influence of "experience" is illustrated in the choice ("preference share") of the GPDS-experienced respondents (having visited the GPDS at least once). For descriptive purpose, table 10 displays the first service choice for the restricted model: the preference for GPDS is stronger (adult scenario: $19 \%$ to $31 \%$, $p=0.020$ ); child scenario: $13 \%$ to $25 \%, p=0.065)$ than in the unrestricted study population. The $\mathrm{p}$ value for the child scenario is slightly above the common critical level of 0.05 , which can be explained by the low number of GPDS experienced. However, overall findings support the trend towards GPDS once the service was experienced. We expect also for the other services a positive impact of experience on choice, but we limit our analysis to the newly established GPDS as the focal point of our study.

\section{DISCUSSION AND CONCLUSION}

Although overall results show that people prefer the ED when in need for medical after-hours care, this study also confirms that people are loyal to the service they have experience with. Experience indeed is the most important factor to choose a service. People having experienced the new GPDS once tend to return to the service. Research in the UK, using other methodologies, also concluded that the loyalty for the GPDS increases when having used it once. ${ }^{25} 32$

The overall results concerning importance and perceived performance are very similar for both scenarios, indicating a high validity of the questionnaire. The most important attribute is "explanation", meaning that the doctor gives information about 
Table 6 ANOVA results for perceived performance and motivation to comply in the child scenario

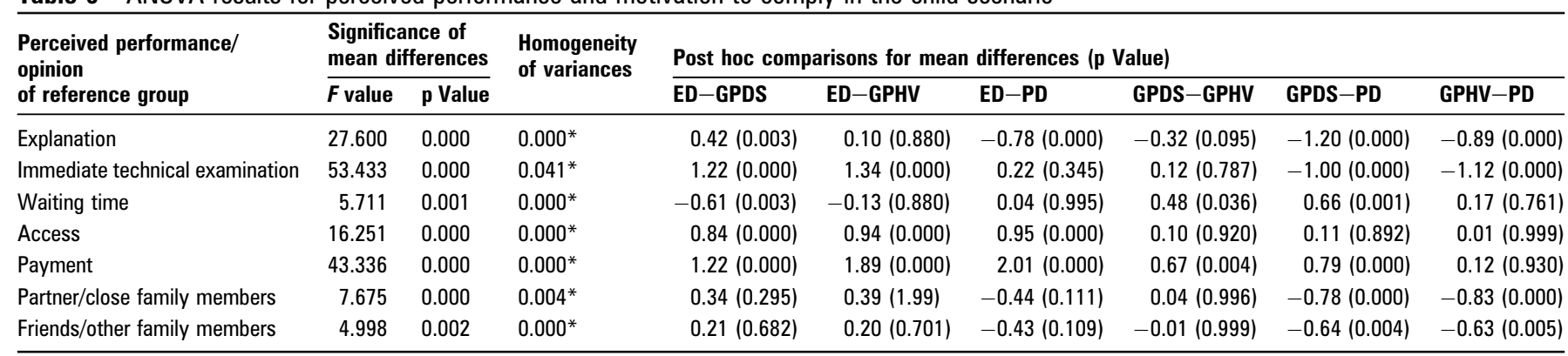

ANOVA, analysis of variance; ED, emergency department; GPDS, general practitioner deputizing services; GPHV, GP home visit; PD, paediatrician.

Applied post hoc test: *Dunnett C.

Table 7 ANOVA results for TRA score in the adult scenario

\begin{tabular}{|c|c|c|c|c|c|c|}
\hline & \multicolumn{2}{|c|}{$\begin{array}{l}\text { Significance of mean } \\
\text { differences }\end{array}$} & \multirow{2}{*}{$\begin{array}{l}\text { Homogeneity } \\
\text { of variances }\end{array}$} & \multicolumn{3}{|c|}{ Post hoc comparisons for mean differences (p Value) } \\
\hline & F value & $\overline{\text { p Value }}$ & & $\overline{\text { ED-GPDS }}$ & ED-GPHV & GPDS-GPHV \\
\hline TRA score & 17.342 & 0.000 & $0.157^{*}$ & $16.359(0.001)$ & $25.336(0.000)$ & $8.977(0.100)$ \\
\hline
\end{tabular}

ANOVA, analysis of variance; ED, emergency department; GPDS, general practitioner deputizing services; GPHV, GP home visit.

Applied post hoc test: *Tukey honest significant difference test.

Table 8 ANOVA results for TRA score in the child scenario

\begin{tabular}{|c|c|c|c|c|c|c|c|c|c|}
\hline & \multicolumn{2}{|c|}{$\begin{array}{l}\text { Significance of } \\
\text { mean differences }\end{array}$} & \multirow{2}{*}{$\begin{array}{l}\text { Homogeneity } \\
\text { of variances }\end{array}$} & \multicolumn{6}{|c|}{ Post hoc comparisons for mean differences ( $p$ Value) } \\
\hline & $F$ value & p Value & & ED-GPDS & ED-GPHV & ED-PD & GPDS-GPHV & GPDS-PD & GPHV-PD \\
\hline TRA Score & 15.552 & 0.000 & $0.003^{*}$ & $22.092(0.000)$ & $28.553(0.000)$ & $8.160(0.297)$ & $6.461(0.507)$ & $-13.932(0.015)$ & $-20.393(0.000)$ \\
\hline
\end{tabular}

ANOVA, analysis of variance; ED, emergency department; GPDS, general practitioner deputizing services; GPHV, GP home visit; PD, paediatrician.

Applied post hoc test: *Dunnett C.

the illness and the treatment. This is confirmed by other researchers: having a doctor who listens, takes time and gives explanation is seen as a key element for successful general practice. ${ }^{25} 263334$ As ED is the most preferred service, our study shows that the main reasons for choosing ED are "sufficient explanation" and "easy access". Consumers also expect immediate technical examination at the ED and when visiting a paediatrician. Compared to the ED and the paediatrician, we found that "waiting time" is the most appreciated attribute at the GPDS.

We used the FNC services and we acknowledge our results may be biased to parents with young children. However, in Belgium, this young population is known to use medical services more than the other groups. ${ }^{27}$ Using this strategy, we were able to acquire a reasonable cross section of the population of the city. In this setting, $44 \%$ of our participants were of foreign origin (foreign nationality currently or at birth). Compared with data of the municipality, $26.8 \%$ of the citizens are of foreign origin, indicating this population was relatively overrepresented in our study. In addition, the level of education differs from data in Belgium. Our respondents had a cumulative percentage of

Table 9 Preference share for both scenarios

\begin{tabular}{lcc}
\hline Service & Adult scenario (\%) & Child scenario (\%) \\
\hline ED & 63 & 47 \\
GPDS & 19 & 31 \\
GPHV & 18 & 13 \\
PD & - & 9 \\
Total & 100 & 100 \\
\hline
\end{tabular}

a degree of lower secondary education or less of $14.3 \%$. In 2004, the data of Flanders mention approximately $18 \%$ of people aged 25 to 34 years having a degree of lower secondary education or less. ${ }^{35}$ In our respondents, we do still lack the group of foreign citizens who do not understand the Dutch, English or modern Arabic language and have a lower educational level. Further qualitative study designs for instance by interviewing stakeholders, who represent these groups, could be used to get more insight in these communities. In this case, contacting imams, spokesmen and youth services of these communities may help clarifying the research question for these specific subpopulations.

Experience has a strong positive influence on choosing a particular after-hours medical service. Especially for the new GPDS, we can conclude that people who have experienced it

Table 10 Preference shares for the different services: full sample versus GPDS experienced sample

\begin{tabular}{llll}
\hline \multicolumn{4}{l}{ Adult scenario preference shares } \\
\hline Service & Full sample (a) (\%) & GPDS experienced (b) (\%) & Difference: $\mathbf{b}-\mathbf{a}^{*}$ \\
\hline ED & 63 & 49 & $-14 \%(0.108)$ \\
GPDS & 19 & 31 & $+12 \%(0.034)$ \\
GPHV & 18 & 19 & $+1 \%(0.747)$ \\
\hline Child scenario preference shares & \\
\hline Service & Full sample (a) & GPDS experienced (b) & Difference: $\mathbf{b}-\mathbf{a}^{*}$ \\
\hline ED & 47 & 44 & $-3 \%(0.905)$ \\
PD & 31 & 27 & $-4 \%(0.720)$ \\
GPDS & 13 & 25 & $+12 \%(0.065)$ \\
GPHV & 9 & 4 & $-5 \%(0.140)$ \\
\hline
\end{tabular}

${ }^{*} p$ Value of significance test of means in parenthesis. 
before are more likely to choose it again. The doctor working at that service needs to offer a clear explanation about the illness and its treatment. To strengthen these effects, the service has to be easily accessible and waiting time must be reduced.

If health authorities want to alter patterns of consumers of medical care by setting up new GPDSs, the first concern has to be to inform people about all the available after-hours services, their specific aims and tasks. To increase the choice for GPDS, authorities need to focus on current non-users of the GPDS and increase their trial rate for this new service. Subsequently, the GPDS should ensure the experience with the service is positive because this facilitates the choice for the same service when in need for help.

Funding Academic funding by the University of Antwerp. Funding by the General Practitioner Deputizing Service of Deurne-Borgerhout-Intercollegiate Center for Management Science Brussels.

Competing interests None.

Ethics approval We received ethical approval of this study from the ethical committee of the University of Antwerp in September 2005 (record no. A 05 45).

Provenance and peer review Not commissioned; externally peer reviewed.

\section{REFERENCES}

1. Boulger JG. Family medicine education and rural health: a response to present and future needs. J Rural Health 1991:7:105-15.

2. Colwill JM. Where have all the primary care applicants gone? [see comment]. N Engl J Med 1992;326:387-93.

3. Fincher R-ME. The road less traveled-attracting students to primary care [see comment]. N Engl J Med 2004;351:630-2.

4. Linzer M, Slavin T, Mutha S, et al. Admission, recruitment, and retention: finding and keeping the generalist-oriented student. SGIM Task Force on Career Choice in Primary Care and Internal Medicine. J Gen Intern Med 1994;9:S14-23.

5. Miller KE, Fox BC, Mitchell GL. Medical students' and private family physicians perceptions of family practice. Fam Med 1996;28:33-8.

6. Stimmel B. The crisis in primary care and the role of medical schools. Defining the issues [see comment]. JAMA 1992: 268:2060-5.

7. Henderson $\mathbf{E}$, Berlin A, Fuller J. Attitude of medical students towards genera practice and general practitioners. Br J Gen Pract 2002;52:359-63.

8. Buesching DP, Jablonowski A, Vesta E, et al. Inappropriate emergency department visits. Ann Emerg Med 1985;14:672-6.

9. Driscoll PA, Vincent CA, Wilkinson M. The use of the accident and emergency department. Arch Emerg Med 1987;4:77-82.

10. Campbell JL, Ramsay J, Green J, et al. Forty-eight hour access to primary care: practice factors predicting patients' perceptions. Fam Pract 2005:22:266-8.

11. van Uden CJT, Winkens RA, Wesseling GJ, et al. Use of out of hours services: a comparison between two organisations. Emerg Med J 2003;20:184-7.

12. Christensen MB, Skafte-Holm P, Weinicke HH, et al. [General practitioners' evaluation of the out-of-hours service in Copenhagen County]. Ugeskr Laeger 2005:167:3412-15.

13. Christensen MB, Christensen B, Mortensen JT, et al. Intervention among frequent attenders of the out-of-hours service: a stratified cluster randomized controlled trial. Scand J Prim Health Care 2004:22:180-6.
14. Vaardal B, Lossius HM, Steen PA, et al. Have the implementation of a new specialised emergency medical service influenced the pattern of general practitioners involvement in pre-hospital medical emergencies? A study of geographic variations in alerting, dispatch, and response. Emerg Med J 2005:22:216-19.

15. Salisbury C. The demand for out-of-hours care from GPs: a review. Fam Pract 2000:17:340-7.

16. Jessopp L, Beck I, Hollins L, et al. Changing the pattern out of hours: a survey of general practice cooperatives. BMJ 1997;314:199-200.

17. Hurst K. British out-of-hours primary and community care: a review of the literature. Int J Health Care Qual Assur Inc Leadersh Health Serv 2006;19:42-59.

18. Campbell N, Iversen L, Farmer J, et al. A qualitative study in rural and urban areas on whether-and how - to consult during routine and out of hours. BMC Fam Pract 2006; 7:26

19. Ajzen I. The theory of planned behavior. Organ Behav Hum Decis Process 1991:50:179-211.

20. http://en.wikipedia.org/wiki/Theory_of_reasoned_action. (accessed 18 Dec 2009)

21. Fishbein M, Ajzen I. Theory-based behavior chānge interventions: comments on Hobbis and Sutton [see comment]. J Health Psychol 2005;10:27-31; discussion 37-43.

22. Fishbein $\mathbf{M}$, Aizen I. Belief, attitude, intention, and behavior: an introduction to theory and research. Belief, attitude, intention, 6 and behavior: an introduction to theory and research, 1975. http://www.people.umass.edu/aizen/fqa1975.html (accessed $18 \mathrm{Dec}$ 2009).

23. Sheppard BH, Warshaw J. The Theory of Reasoned Action: a meta-analysis of pas research with recommendations for modifications and future research. Journal of Consumer Research: An Interdisciplinary Quarterly 1988;15:325.

24. Ajzen I, Albarracin D, Hornik R, eds. Prediction and change of health behavior: applying the reasoned action approach. Mahwah, NJ: Lawrence Erlbaum Associates, 2007:328.

25. Scott A, Watson MS, Ross S. Eliciting preferences of the community for out of hours care provided by general practitioners: a stated preference discrete choice experiment. Soc Sci Med 2003;56:803-14.

26. Morgan A, Shackley P, Pickin M, et al. Quantifying patient preferences for out-ofhours primary care. J Health Serv Res Policy 2000;5:214-18.

27. Gourbin C, du Bollay D, Philips $\mathrm{H}$, et al. Evaluatie van forfaitaire persoonlijke bijdrage op het gebruik van spoedgevallendiensten. Brussel: Federaal Kenniscentrum voor de Gezondheidszorg (KCE); juli 2005 2005. KCE Reports vol. 19A. Ref. D/2005/10.273/21 http://www.kce.fgov.be/index_nl.aspx? SGREF $=5270 \& C R E F=5363$ (accessed 18 Dec 2009).

28. McClay JC, Campbell J. Improved coding of the primary reason for visit to the emergency department using SNOMED. Proceedings/AMIA, 2002. Annual Symposium: 499-503

29. Jaarverslag Kind en Gezin. 2005 http://www.kindengezin.be/lmages/ JV2005 tcm149-46570.pdf (accessed 18 Dec 2009).

30. Shipman C, Longhurst S, Hollenbach F, et al. Using out-of-hours services: general practice or A\&E? Fam Pract 1997;14:503-9.

31. WHO. The world health report. Primary Care: now more than ever, 2008. http://www. who.int/whr/2008/en/index.html.

32. Rajpar SF, Smith MA, Cooke MW. Study of choice between accident and emergency departments and general practice centres for out of hours primary care problems. $J$ Accid Emerg Med 2000;17:18-21.

33. Vick S, Scott A. Agency in health care. Examining patients' preferences for attributes of the doctor-patient relationship. J Health Econ 1998;17:587-605.

34. Kroneman MW, Maarse $\mathrm{H}$, van der Zee J. Direct access in primary care and patien satisfaction: a European study. Health Policy 2006;76:72-9.

35. VRIND: Vlaamse Statistieken, Strategisch Management en Surveyonderzoek, 2006 http://aps.vlaanderen.be/statistiek/publicaties/stat_Publicaties_vrind2006.htm (accessed 30 Jan 2008) 